\title{
LA ESTEREOTOMIA COMO FUNDAMENTO CONSTRUCTIVO DEL RENACIMIENTO ESPAÑOL
}

\author{
(STEREOTOMY AS A BUILDING BASIS IN THE SPANISH RENAISSANCE)
}

José Carlos Palacio González, Arquitecto

\section{RESUMEN}

Es en el Renacimiento cuando la estereotomía cobra su máxima dimensión, una de las técnicas más asombrosas de la construcción. En este artículo se hace una breve exposición de algunas de las pautas fundamentales que nos permitan acercarnos a una interpretación del arte de la cantería tal y como fuera conocido en el siglo XVI.

Al acercarnos al Renacimiento español conviene, en primer lugar, llamar la atención sobre dos puntos de gran interés:

- la construcción, durante el mismo, y

- los tratados del arte de la cantería a través de los siglos.

\section{SUMMARY}

Stereotomy, one of the most amazing techniques in the field of construction, reaches its peak in the Spanish

Reanaissance. This article briefly sets out some of the basic rules which bring us closer to an interpretation of the art of stonemasonry such as it was known in the XVI Century.

When dealing with the Spanish Renaissance, it is advisable to draw attention to, first of all, two points of great interest:

- construction at that time, and

- the treatises on the art of stonemasonry through the centuries.
La estereotomía es hoy día una ciencia muerta. No obstante, el calor de su extraordinario pasado todavía nos alcanza. El brillo de las espléndidas realizaciones que a través de ella se ejecutaron impresionan, desde su silencio, nuestros ánimos vivamente. Sin embargo, el conocimiento de unas técnicas constructivas que hicieron posible el protagonismo de la piedra como soporte constructivo permanece en el más remoto olvido.

Durante siglos fue perfeccionándose en nuestro pais desde las épocas más remotas del medievo hasta el Renacimiento en que la estereotomía cobra su máxima dimensión una de las técnicas más asombrosas de construcción. Esta trayectoria de siglos se hace por fuerza difícil concentrarla para su exposición, en las escasas dimensiones que un artículo requiere. No obstante, intentaremos aquí exponer algunas de las pautas fundamentales que nos permitan acercarnos a una interpretación del arte de la cantería tal y como fuera conocido en el siglo XVI.
Al acercarnos al Renacimiento español desde este enfoque, convendrá indicar algunos aspectos de carácter general que nos ayuden a delimitar el contexto en que la cantería tiene lugar en nuestro país. Asi pues, conviene en primer lugar llamar la atención sobre dos hechos de extraordinario interés:

\section{A) La construcción del Renacimiento español}

Sin duda, desde un enfoque puramente constructivo, una de las cualidades más sobresalientes de nuestro Renacimiento se fundamenta en el hecho de que la mayor parte de la actividad edilicia que se lleva a cabo durante este período se ejecuta usando la piedra como materia de construcción.

Esta peculiaridad es, sin duda, notable teniendo en cuenta que si bien el Renacimiento es un fenómeno cultural de origen italiano que se expande internacio- 


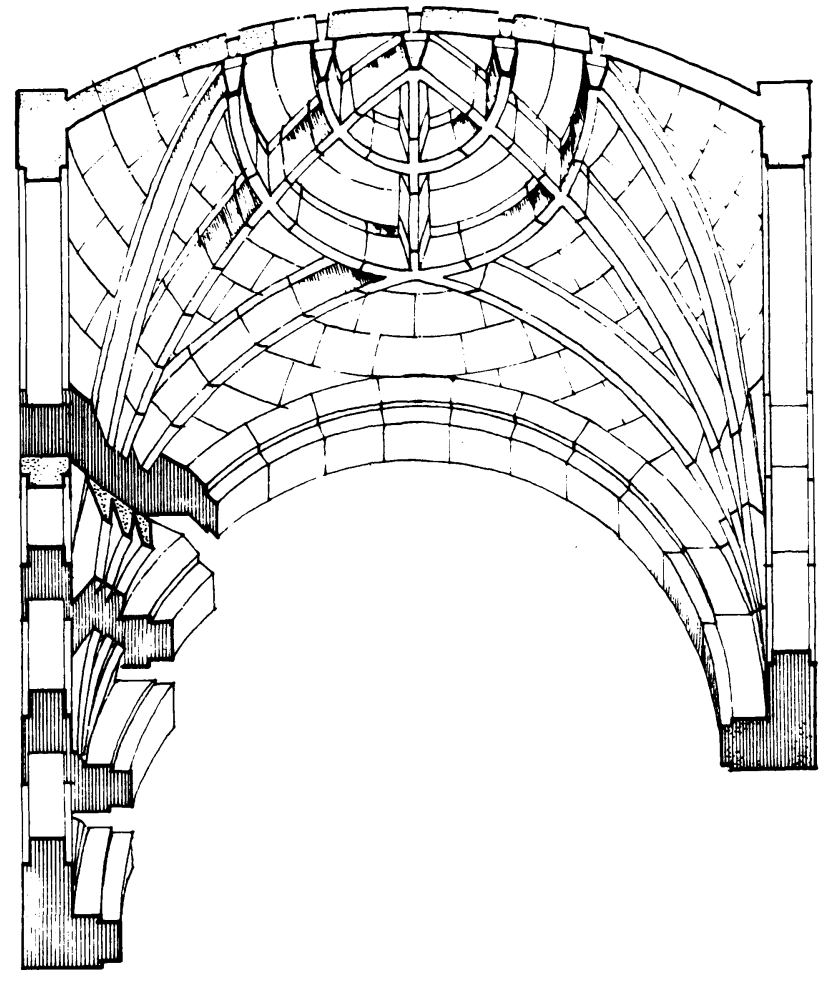

Fig. A.-Bóveda vaida de dovelaje esférico y nervaturas decorativas góticas.

nalmente por Europa tiene, en nuestro país, formas de interpretarse desde lo constructivo, radicalmente diferentes. Así, mientras que en Italia el Renacimiento va a desarrollar con carácter preeminente la técnica de la albañilería, en nuestro país la cantería es el oficio que tendrá a su cargo la mayor parte de la actividad edificatoria durante el siglo XVI (1).

Esta particularidad que acabamos de exponer no es privativa del Renacimiento español, sino que, como en el caso francés, se da en aquellos paises en que la tradición de un pasado medieval construido en piedra sobrevive al cambio estilístico que supone el siglo XV (2). Una sensibilidad emotiva de la colectividad frente al edificio terminado en piedra, junto a unas técnicas constructivas avaladas por las centurias precedentes hacen pervivir, por tanto, una forma de entender y ejecutar la arquitectura.

Sin embargo, cabe suponer un enorme esfuerzo investigador por parte de los técnicos y arquitectos del Renacimiento, al verse obligados a adaptar sus conocimientos de cantería medievales hacia los nuevos modelos que, provenientes de Italia, van Ilegando a nuestro país hasta conseguir, poco a poco, sustituir definitivamente las ojivas medievales por los desarrollos de superficies cilindricas y esféricas basadas en el arco de medio punto.
Con objeto de ilustrar lo que podíamos considerar un cierto eclecticismo constructivo entre técnicas medievales adaptadas a la formalización clásica, veamos dos ejemplos de Alonso de Vandelvira. En primer lugar (fig. A), se trata de la adaptación de la bóveda ojival de nervaturas gótica y su adecuación a la esfericidad de las bóvedas que el Renacimiento demanda. Obsérvese que la plementería deja de apoyarse sobre las ojivas para constituirse en un sistema estructural cualitativamente autónomo, de tal forma que, al conformarse como un sistema de dovelas en "vuelta de horno" va a ser precisamente la plementeria la que cobra el papel sustentante de la bóveda, mientras que las nervaturas, relegadas a un papel decorativo, habrán de sujetarse a ellas mediante colas (3).

Un poco más avanzado en esta línea que vamos exponiendo podría ser la interpretación que el Renacimiento español hace de la bóveda de casetones romana. Los arquitectos de nuestro Renacimiento van a entender esta bóveda aligerada, con una mentalidad absolutamente medieval y, en tal sentido, procederán a descomponerla en nervios y plementos formando una retícula ortogonal que permita cerrar la superficie esférica de la bóveda (fig. B).

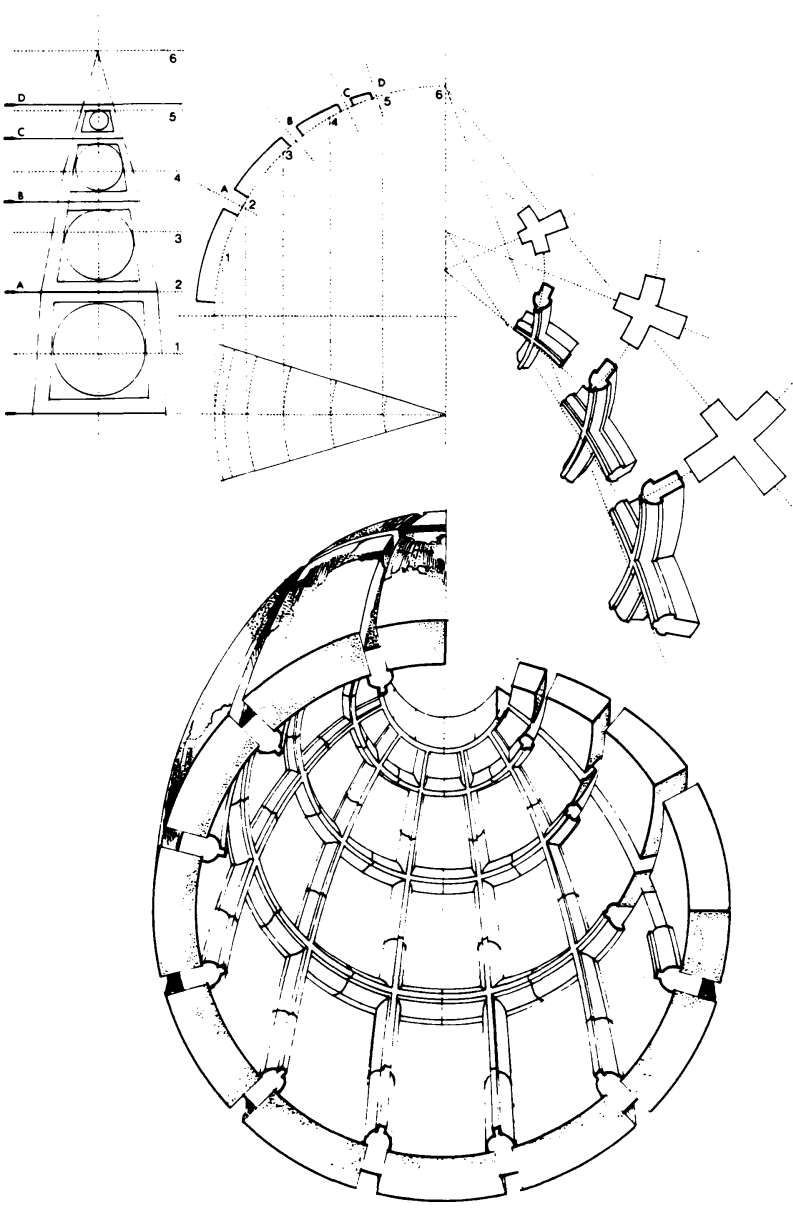

Fig. B.-Bóveda de casetones interpretada mediante una retícula de nervaturas. 


\section{B) Los tratados}

Como resultado de este esfuerzo investigador por adaptar una tecnología medieval a los modelos clásicos, nuestro pais presenta una caracteristica de indudable interés y es el hecho de contar con la más amplia bibliografía sobre cantería que ningún otro país europeo pueda ofrecer durante este período. Superado ya el "perpetuo silencio" con que Benito Bails (4) se refería al ocultismo de las técnicas de construcción que mantenía el prestigio de los poderosos gremios de la cantería medieval, los técnicos del Renacimiento pondrán en circulación sus hallazgos y recursos constructivos; ello ha permitido que hoy dia algunos de aquellos manuscritos hayan llegado hasta nosotros.

Tal es el caso de Alonso de Vandelvira (5), sin duda alguna el más completo tratado de cantería renacentista que se conserva en Europa. Su estudio nos ha permitido desvelar algunas de las incógnitas de las épocas más oscuras y también apasionantes de la construcción española. Junto a este tratado hemos de citar el de Hernán Ruiz el Joven (6), arquitecto sevillano que nos dejó un tratado impregnado de un contenido más humanista, a la manera de los grandes tratadistas italianos, en el cual aparecen indicaciones de despieces de cantería de gran interés. Ginés Martínez de Aranda (7) es el autor de otro tratado de contenido netamente dedicado al arte de la labra de piedra; $y$, por último, tendremos que citar algunas observaciones constructivas de Rodrigo Gil (8) insertas en el tratado "Compendio y simetría de los templos".

Frente a esta producción española y a título de comparación, no encontramos en Francia, durante el siglo $\mathrm{XVI}$, más que un sólo tratado de las características que comentamos. Así, hemos de citar el espléndido tratado de Philibert de L'Orme (9) "Architecture". Como prueba del desinterés italiano por la cantería no aparecerá ningún tratado que se ocupe de estos temas hasta bien entrado el siglo XVIII con Guarini (10).

\section{La cualidad dimensional}

Estereotomía es la palabra con que modernamente designamos una serie de actividades relacionadas con el corte de piedra destinada a la construcción. No obstante, la pérdida de uso de esta técnica constructiva hace que hoy dia aparezca desdibujado el ámbito específico de su aplicación. En tal sentido, sería oportuno establecer algunas ideas de carácter general que nos ayuden a establecer, más concretamente, el marco en que se desenvuelve la estereotomía.

Asi pues, retomando esta dualidad de oficios a la que haciamos referencia en un principio: albañileria y estereotomía, si tuviéramos que definir una cualidad que delimite ambos oficios, habria que buscarla precisamente en las relaciones dimensionales de la pieza unitaria que vamos a emplear: el ladrillo y la dovela.

En albañileria, el ladrillo es una pieza relativamente pequeña respecto a la superficie abovedada que se pretende ejecutar. Ello permite que pueda considerarse como un elemento indiferenciado y, como consecuencia de lo cual, todos los ladrillos podrán ser iguales; la simple yuxtaposición de unos sobre otros, unidos mediante un mortero, permitirá acometer la construcción de cualquier superficie geométrica. Obsérvese que en cantería el proceso es radicalmente distinto, ahora la dovela tiene un tamaño notablemente mayor respecto a la superficie a construir, lo cual obliga a una exacta definición de dimensiones de la misma para que, una vez tallada la piedra, podamos tener la seguridad de que se va a producir un acoplamiento perfecto entre dovelas.

Por tanto, el tamaño de las piezas de piedra que constituyen una bóveda es una cualidad fundamental a la hora de valorar el grado de calidad de la misma, ya que sería posible reducir lo suficiente el tamaño del dovelaje hasta conseguir que ya no fuera necesario proceder al diseño previo de las dovelas, y así podría llevarse a cabo la construcción de un edificio con apariencia pétrea en el cual el oficio que lo posibilita estaría más próximo a la albañilería que a la cantería.

\section{La geometría}

En el apartado anterior se hizo referencia al problema de la definición de dimensiones de una dovela. Esta actividad fundamental de la estereotomía va a ser posible gracias a la geometría. Asi pues, mediante diversas operaciones geométricas, el maestro cantero del Renacimiento necesita calcular las dimensiones de las caras de cada dovela para proceder a la talla de la misma.

Ahora bien, si pensamos en la extraordinaria complejidad que puede tener cada una de estas piezas, el problema geométrico que es preciso resolver empieza a cobrar sus verdaderas dimensiones; baste, a tal fin, pensar en una sola dovela de, pongamos por caso, una bóveda de media naranja; en este tipo de bóvedas cada dovela es un prisma trapezoidal definido por ocho vértices que se unen entre sí mediante caras cóncavas y convexas. Sólamente sus caras laterales verticales permanecen planas, si bien afectadas de un oportuno derrame hacia el centro de la bóveda.

Sin perjuicio de volver sobre este problema más exhaustivamente a través de los ejemplos que más adelante se estudiarán, sería oportuno ahora anunciar que la operación geométrica fundamental de toda la estereotomía renacentista se basa en el desarrollo de superficies cónicas. 
Los aspectos geométricos que acompañan el arte de la labra de piedras son interesantes, no sólamente porque permiten explicarnos los complejos problemas de diseños de dovelas, sino que, además, permiten conjeturar interesantes observaciones ya que es de común acuerdo que fueron precisamente los maestros canteros medievales y renacentistas quienes, a través de su oficio, sentaron las bases de la actual geometria. En este sentido, podría afirmarse que si, en nuestro país, la cantería jugó un papel preeminente, también España debió forzosamente jugar un papel de primer orden en la cristalización de la ciencia que hoy día conocemos como Geometría Descriptiva, por lo menos en sus facetas más vinculadas al sistema diédrico de proyección.

\section{La transmisión de datos}

Volviendo nuevamente a la dovela de la bóveda de media naranja que, como ejemplo, describimos anteriormente y, una vez determinadas sus dimensiones, resta ahora un nuevo problema: se trata de la transmisión de los datos y medidas que la acotan, máxime si se piensa que estas medidas estaban destinadas a un personal de cantera que hemos de suponer poco especializado en la lectura de planos.

Con la mentalidad cartesiana que hoy día es herramienta común para la definición de los objetos destinados a ser construidos o fabricados en taller, se hace difícil pensar a través de qué tipo de plantas y secciones acotadas podría definirse la dovela trapezoidal a la que venimos aludiendo. Pues bien, a tal efecto, el maestro cantero renacentista va a usar patrones de cada una de las caras de dicha dovela. Según la complejidad de cada cara serán necesarios más o menos patrones pero, concretamente para la dovela de bóveda esférica que hemos tomado como ejemplo, bastará con el patrón de su cara de intradós, es decir, la proyección plana de la cara que quedará vista desde el interior una vez cortada la bóveda. El problema, por tanto, empieza a simplificarse considerablemente.

El hecho de que la transmisión de datos y medidas de las dovelas se efectúe sobre patrones tiene algunas implicaciones interesantes que merecen la pena ser destacadas:

a) En primer lugar, pensemos que el arquitecto trabajaria en su taller confeccionando los distintos patrones a escala reducida y posteriormente estos patrones se ejecutarian a tamaño natural para proceder a la talla de la piedra. No obstante, este cambio de escala es una operación delicada que, en caso de error, conllevaría a la talla de multitud de piezas inservibles por su incapacidad de adaptarse unas con otras. Por tanto, cabe pensar que los dibujos del maestro cantero estarian destinados a ser reproducidos a tamaño natural durante el transcurso de la obra, al objeto de obtener los patrones con la mayor exactitud.

Así pues, cabe imaginarse la obra renacentista de cantería acompañada de gigantescos dibujos geométricos ejecutados en el suelo o paredes del propio edificio en construcción, de los cuales se irian obteniendo los diversos patrones a tamaño natural que permitirian taIlar las dovelas capaces de cerrar las bóvedas con exactitud (11).

b) En segundo término los patrones introducen variables en el proceso constructivo que posibilitan una extraordinaria flexibilidad laboral, ya que permitirán al arquitecto el control exhaustivo de la obra sin necesidad de estar presente en la misma. Ello permite, en gran medida, explicarnos la extraordinaria actividad laboral que documentalmente atribuimos a nuestros grandes maestros del Renacimiento, incompatible, sin duda, con la extraordinaria longevidad de las obras.

Todo ello nos conduce a pensar que un maestro de cantería podría ejecutar los patrones previo conocimiento de medidas de replanteo en una ciudad lejana al punto en que las obras se están llevando a efecto; estos patrones serían enviados a las obras o a las canteras y desde allí llegarian las dovelas perfectamente talladas al lugar donde habrian de emplazarse definitivamente.

También en cantera los patrones permiten una notable racionalización del trabajo, ya que el personal destinado a la labra de la piedra podría dividirse en cuadrillas que, dotadas de su correspondiente patrón, se dedicarían a la talla de la misma dovela; como una bóveda esférica requiere tantos patrones distintos como hiladas horizontales compongan su superficie, así pues el trabajo en cantera se dividiria en tantas cuadrillas como hiladas tenga la bóveda, con lo que las dovelas resultantes, perfectamente codificadas por hiladas, irian llegando a la obra. Unicamente el maestro cantero que calculó las trazas de los patrones tendrá la seguridad de que todas aquellas dovelas irán acoplándose perfectamente unas a otras hasta conseguir cerrar la clave de la bóveda.

\section{El utillaje}

Antes de pasar a analizar algunos ejemplos concretos, querría llamar la atención del lector sobre algunos instrumentos de cantería. Hasta nosotros ha llegado una buena cantidad de instrumentos de corte de piedras que han sobrevivido al paso de los siglos. Se trata de los conocidos cinceles, sierras, martillos y picos de desbaste, etc. No obstante, los instrumentos fundamentales de cantería, aquellos que permitirán realizar los cortes oportunos de las dovelas para que éstas que- 


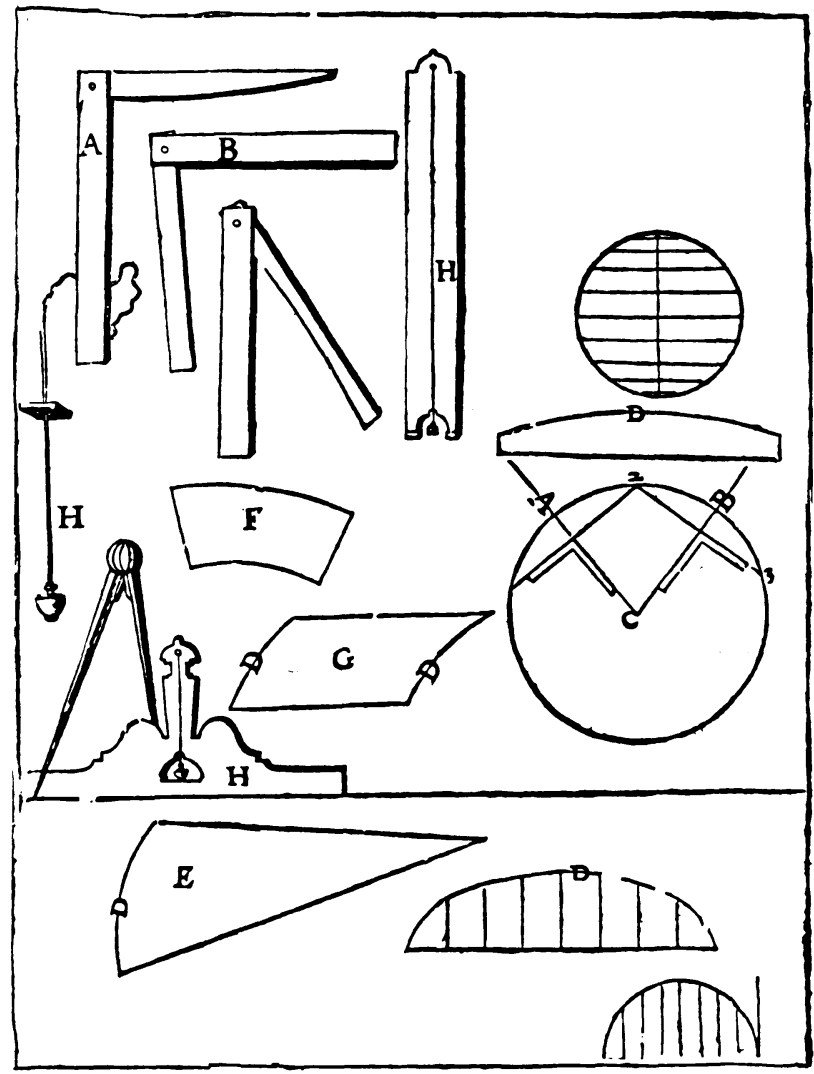

Fig. C.-Diversos instrumentos de canteria: baibeles, saltarreglas y patrones en una interpretación de Phillihert de L'Orme: "Architecture".

den perfectamente pañeadas con los planos de facha$\mathrm{da}$, o bien aquellos instrumentos que van a posibilitar los oportunos derrames y concavidades de las dovelas que componen las cáscaras esféricas han desaparecido con el tiempo. Su uso aparece hoy como dudoso e incierto. Se trata de los baibeles y saltarreglas.

Como puede apreciarse en la figura C, los instrumentos a los que nos referimos son de fácil y rápida fabricación, probablemente construidos de madera, y básicamente se trata de escuadras, con uno de sus brazos rectos mientras que el otro podrá adoptar curvaturas variables. El baibel tiene su articulación siempre fija y sirve para tallar, usándolo como maestra, las distintas concavidades de las dovelas, mientras que la saltarregla suele tener su ángulo articulado, lo cual, en definitiva, la convierte en un transportador de ángulos cuya misión está ligada al corte de las testas de las dovelas al objeto de que se adapten a los paños verticales de fachada.

Aunque más adelante tendremos ocasión de conocer detenidamente sus posibilidades de uso, interesa destacar aquí cómo tanto estos instrumentos como los patrones son en realidad fabricados específicamente para tallar la pieza arquitectónica que se pretende construir, sea por ejemplo una bóveda por aristas o una media naranja y así, una vez terminada ésta, todo este utillaje sería abandonado al haber dejado de tener la menor utilidad, con lo cual se produce el hecho paradójico de que el propio instrumental de la cantería encierra, con su desaparición, la posibilidad de explicarnos hoy dia las razones constructivas que permitieron la edificación de las grandes obras de cantería de nuestro pasado.

\section{El tallaje de la piedra}

Para proceder al tallado de las dovelas de cualquier elemento arquitectónico existen dos posibles caminos. Dependiendo de la vía que se tome, los patrones y datos geométricos a tener en cuenta pueden variar sensiblemente. También es verdad que no todos los elementos son susceptibles de ser tallados de las dos formas que a continuación se van a exponer. Asi, por ejemplo, una bóveda de cañón admitiria, para la talla de sus dovelas los dos procesos de talla, mientras que una cúpula de media naranja sólo permite la talla de sus dovelas a través de uno de los métodos (12).

Para clarificar ambos extremos obsérvese la figura $D$, en la cual puede verse, en primer lugar, las figuras a) y b), las dos formas de talla de una bóveda de cañón o una bóveda por aristas. (Pág. siguiente).

En primer lugar, observemos la figura a que representa el método de corte que recibía el nombre de método de corte "por robos" ya que se trata de ir robando al prisma de piedra contenedor de la dovela los cuatro triángulos residuales que recuadran la silueta de la testa de la dovela. Por tanto, esta forma de talla requiere obtener un patrón rectangular que circunscriba la silueta de la testa de la dovela. En un arco o bóveda de cañón en el cual todas las dovelas son iguales bastará con un sólo patrón rectangular para proceder a la talla de todas las dovelas. No obstante, si lo que pretendemos ejecutar es una bóveda de cañón (fig. E) o un rincón de claustro (fig. F), cada una de las dovelas ha de llevar su correspondiente recuadro al objeto de que, al aplicar el patrón nuevamente en dirección ortogonal, se produzca la arista oportuna que permita el enlace entre las dos hiladas.

El segundo método que se expone en la figura $D$. b) es el método de corte "por caras". Se parte ahora del patrón rectangular obtenido por la proyección plana de una de las dovelas. Para poner en práctica este método de corte es preciso construir un baibel tal y como se aprecia en el dibujo. Se trata de una escuadra fija de dos brazos, uno de los cuales está curvado con el mismo radio de la bóveda y el otro es recto y orientado hacia el centro de la misma.

Con el baibel y el patrón de la cara de intradós se comenzará a trabajar la pieza en vertical, descantillando 

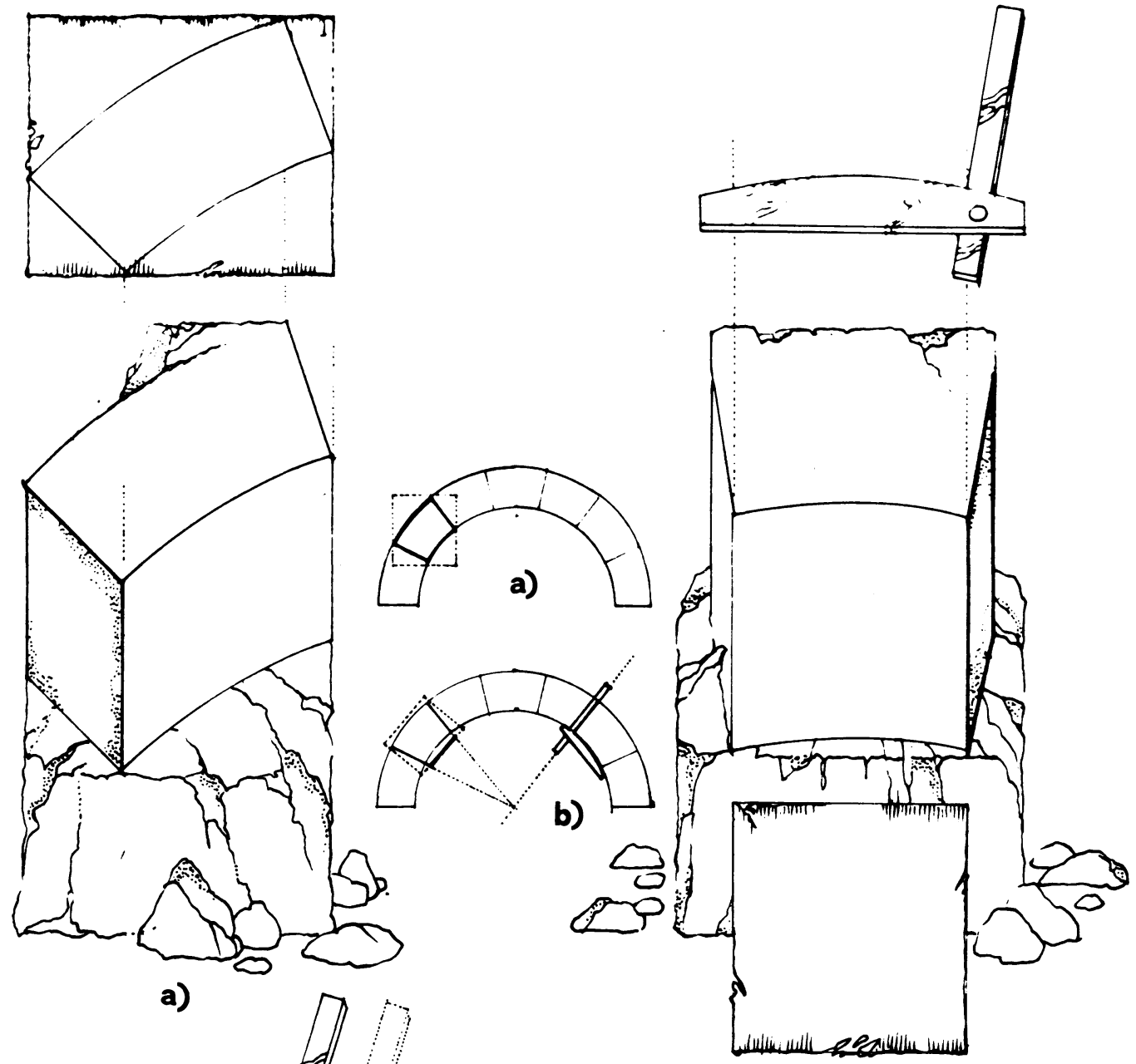

a)
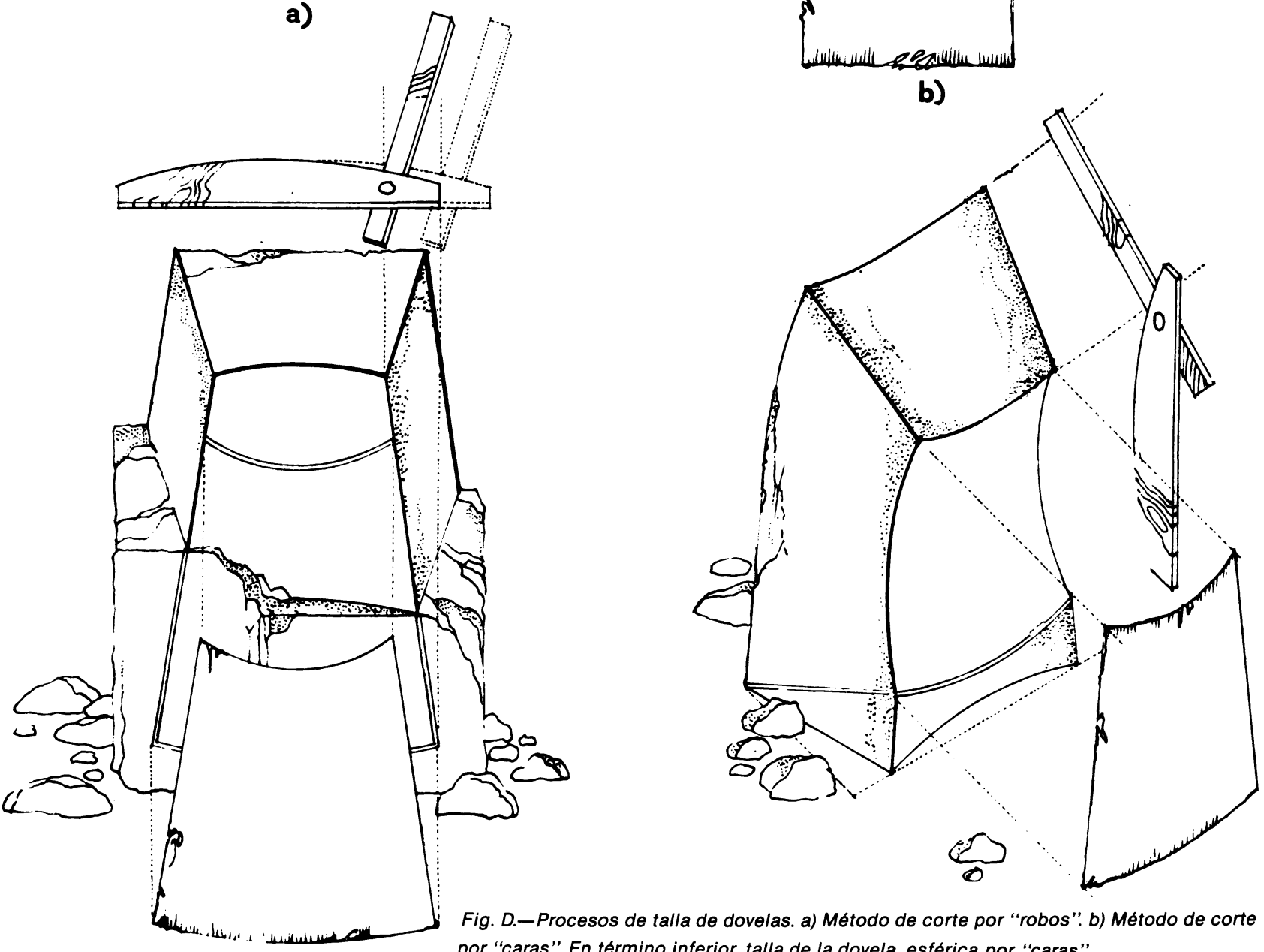

Fig. D.-Procesos de talla de dovelas. a) Método de corte por "robos". b) Método de corte por "caras". En término inferior, talla de la dovela esférica por "caras". 


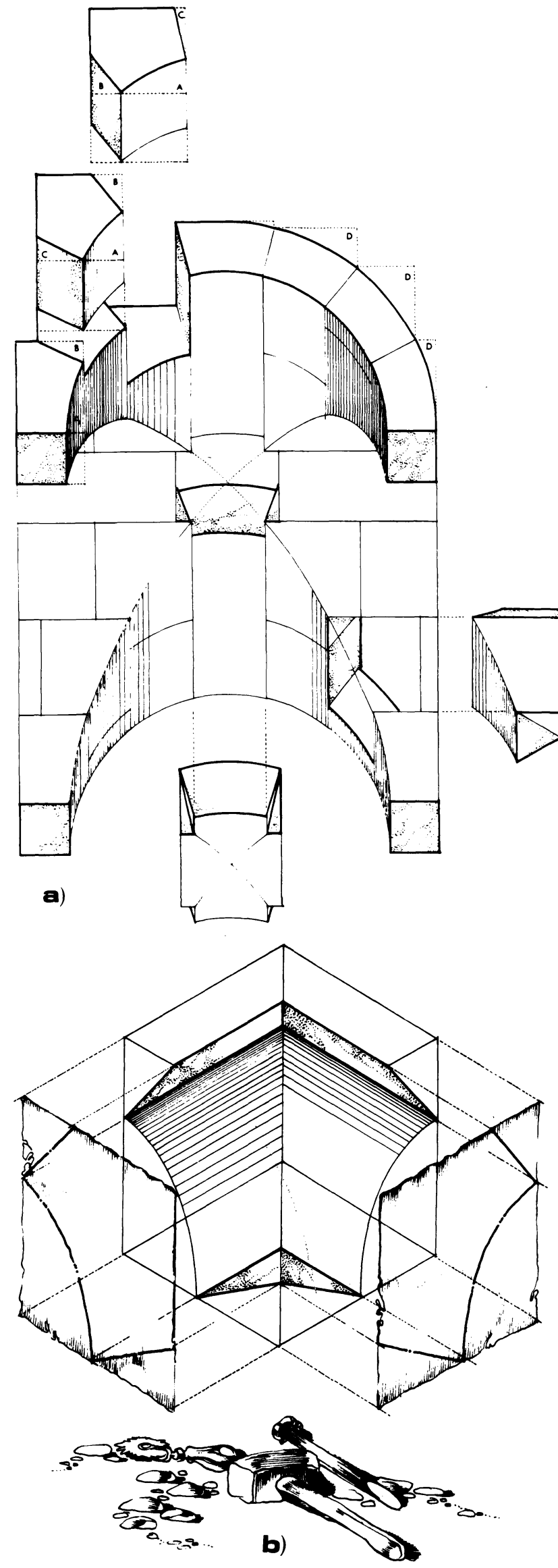

Fig. E.-a) Despiece de dovelas de la bóveda por aristas. b) Talla de la dovela de la bóveda por aristas.

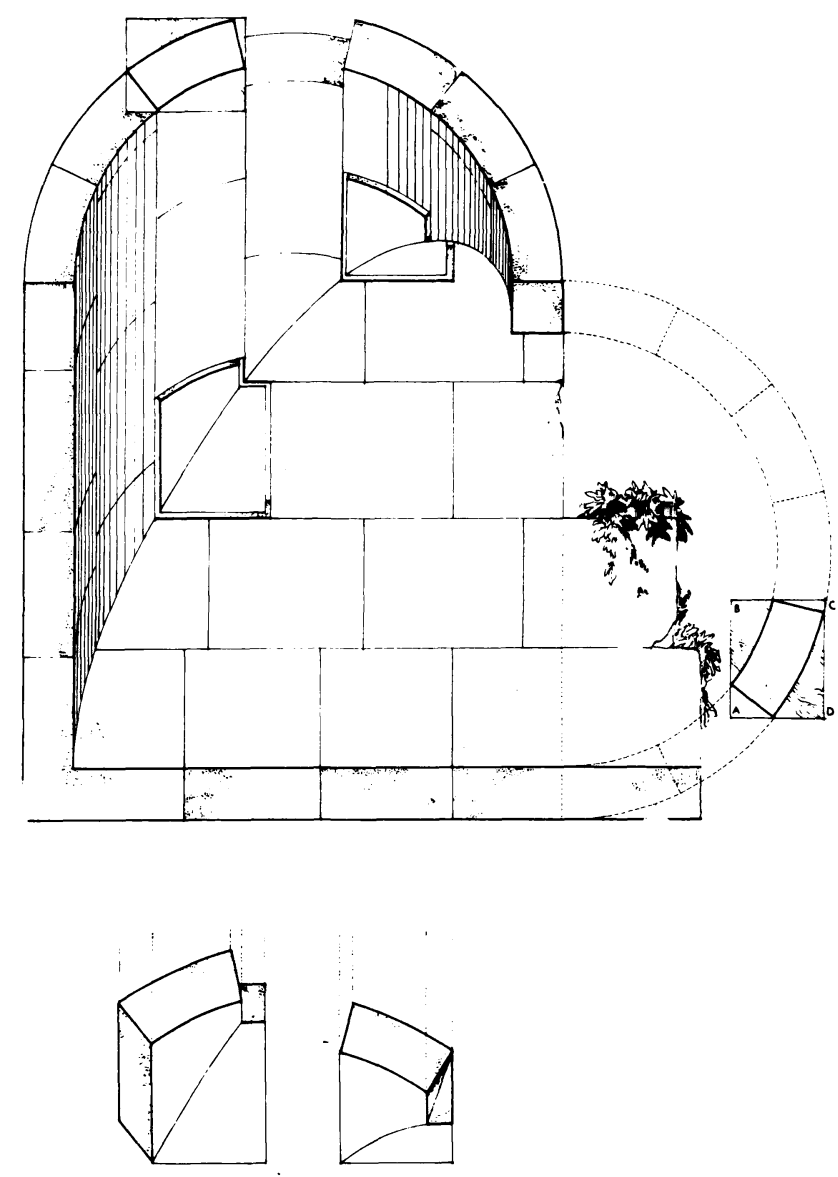

Fig. F.-Rincón de claustro.

la piedra que queda fuera del ángulo del baibel. De esta forma, de una "tirada" de baibel, se obtienen la curvatura interior y el derrame de una de sus caras; a continuación, dando la vuelta al baibel, obtendremos el derrame de la otra cara.

\section{El desarrollo de las superficies cónicas: las trompas}

Como vehículo de transmisión de cargas las trompas, no cabe duda, eran un instrumento ingenioso y oportuno cuyos orígenes hay que buscarlos en los remotos tiempos del Románico. Su uso para soportar ochavos era especialmente adecuado en los cimborrios medievales, pero entrañan dificultosos problemas de sintaxis cuando sobre ellas se hacen descansar espacios cupulados de planta redonda, ya que el apoyo de la bóveda sobre la trompa se reduce a un punto sobre la clave; el resto de su arco de embocadura debe enlazarse con el plano de imposta de la cúpula mediante dos pequeños triángulos esféricos; en realidad, dos pequeñas pechinas, lo cual, con el tiempo, llevó, sin duda, a ir sustituyendo este complejo sistema de trompa y pechinas por uno solo: las grandes pechinas del Renacimiento. 


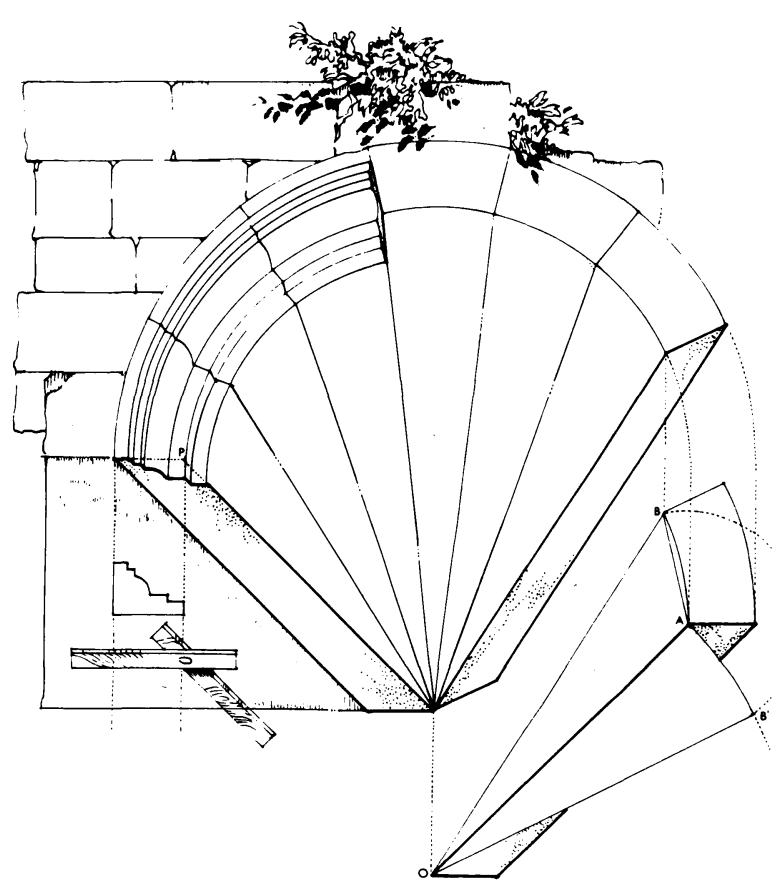

Fig. G.-Diseño de patrones de la trompa recta.

Para tallar el dovelaje de una trompa pueden necesitarse, según la complejidad de ésta, muchos datos y patrones, pero si lo que se pretende ejecutar es una trompa recta, es decir, planta en rincón a $45^{\circ}$ y embocadura en arco de medio punto (fig. G), basta con un solo patrón, que es precisamente el de la cara de intradós de una de las dovelas. Este patrón se obtiene desarrollando en el plano horizontal la superficie cónica de la trompa. A tal efecto, trácese con un compás que tenga por centro el vértice de la trompa y como radio la generatriz del cono un círculo al que posteriormente se irá fragmentando, con la medida de la longitud de la dovela, en tantas partes como dovelas contenga la trompa.

El patrón así obtenido permitirá la talla de un prisma de piedra triangular al cual podrá dársele la concavidad interior, sin más que hacer pasar una regla como maestra por su cara interior que, fija en su vértice, describa un círculo que indica el dibujo de la testa de la dovela.

Resta, por último, un problema delicado cual es cortar debidamente el extremo exterior de las dovelas al objeto de que se acomoden al plano vertical de la fachada. Para llevar a cabo esta operación se construirá una saltarregla (fig. G).

Se trata, sencillamente, de una escuadra articulada, en este caso de brazos rectos, que va a permitir transportar ángulos. En el caso de la trompa que estamos examinando, este ángulo es igual para todas las dovelas y es precisamente el que, en las impostas, forma la junta interior de las dovelas con el plano vertical de la pa- red. Bastará, pues, con colocar las saltarreglas en las paredes laterales de la dovela que acabamos de tallar y, de acuerdo con el ángulo que marque, se procederá a cortar la testa de esta pieza con la seguridad de que, una vez colocada en su posición, quedará perfectamente pañeada con el plano vertical de la pared.

\section{Las trompas irregulares}

El problema puede llegar a complicarse algo más si la trompa fuera irregular, ya que en tal caso tanto los patrones de las caras interiores como las saltarreglas de cada una de las juntas con el plano vertical van variando entre las distintas dovelas. La figura $\mathrm{H}$ nos presenta este caso en una trompa simátrica; por tanto, la resolución de esta pieza pasa por la obtención de los patrones y saltarreglas de las dovelas que componen una mitad.

Veamos, pues, cómo obtener este primer patrón. La figura H.3 representa el dibujo de la proyección horizontal de esta trompa, el cual servirá para ir abatiendo las juntas inclinadas que van formando las distintas dovelas entre sí y, con ello, obtener las verdaderas mag-

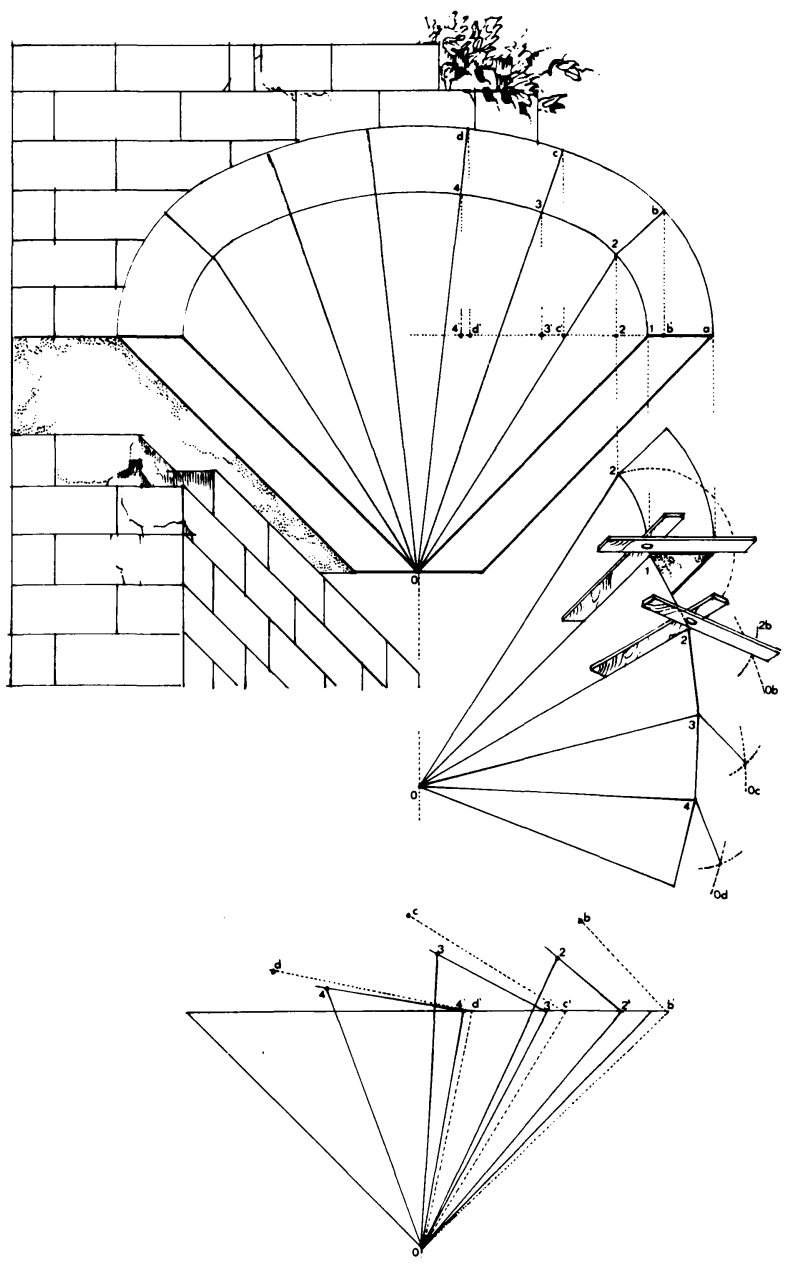

Fig. H.-Diseño de patrones y saltarreglas de la trompa escarzana. 


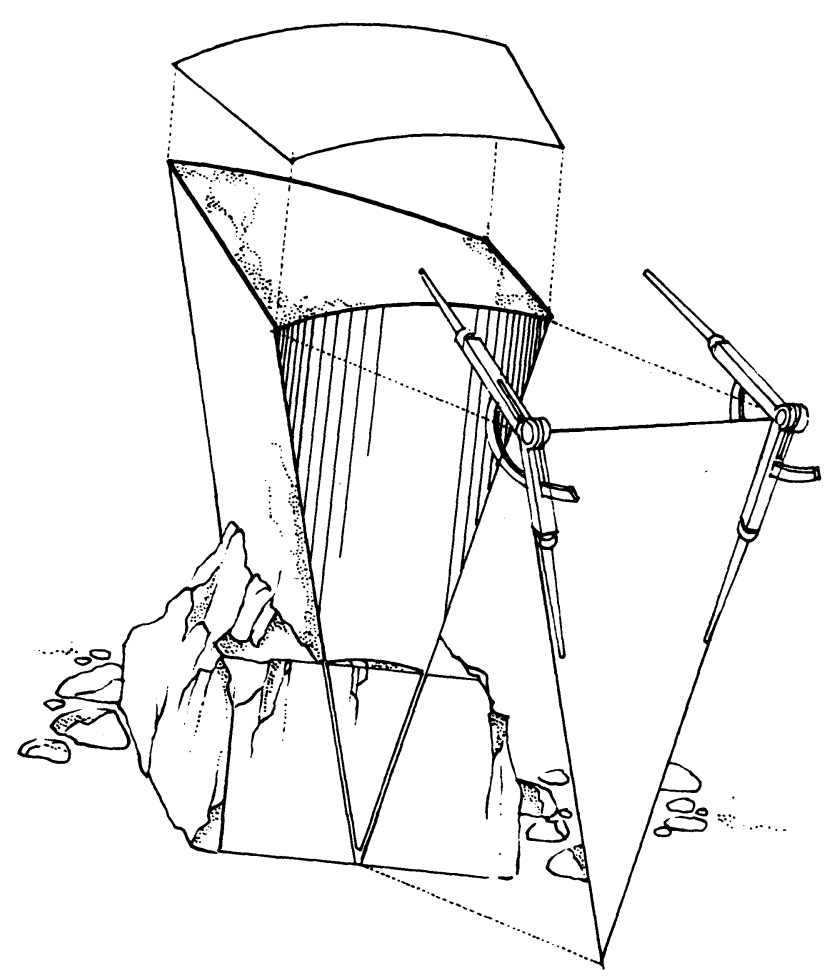

Fig. I.-Talla de la dovela de la trompa escarzana o aplicando patrones y saltarreglas.

nitudes de éstas. Con estos datos podremos ir reconstruyendo cada uno de los patrones tal y como aparece en la figura H.2. Así, para obtener el primer patrón, bastará con trazar un círculo con la medida real de la junta 0,2 , tomando como centro el punto $0 \mathrm{y}$, posteriormente, fraccionarlo con la medida 1,2 que es la anchura por la testa de esta primera dovela, todo lo cual nos define el punto 2 y con él el triángulo $0,1,2$ que es el primer patrón. Sucesivamente irán obteniéndose el resto siguiendo las mismas pautas.

Resta ahora calcular las diversas saltarreglas ya que, salvada la primera, sobre el plano de impostas, que resulta aparente en el dibujo, el resto requieren un cálculo específico de cada una de ellas, ya que, a diferencia de la trompa anterior, ahora las saltarreglas van variando entre cada dovela. Estos ángulos se han calculado en la figura $\mathrm{H} .3$ a través de los oportunos abatimientos, similares a los ya utilizados en el caso de los patrones. El lector podrá ir reconstruyéndolos sin necesidad de extendernos aquí en explicaciones más dilatadas.

Para resumir el proceso de talla de este tipo de dovelas, bastará con observar la figura I, en la cual se hace uso de los patrones y saltarreglas tal y como más arriba fue comentado.
Las circunstancias que pueden afectar a las trompas son extraordinariamente variadas. Sin embargo, los principios por los que se rige la talla de sus dovelas son similares a los expuestos en los párrafos anteriores. A título de ejemplo, pueden observarse en la figura $\mathrm{J}$ tres ejemplos que nos ilustrarán al respecto:
a) trompa en esquina apuntada,
b) trompa de Montpeller,
c) trompa en torre cavada.

\section{La estereotomía de la esfera}

Si tuviéramos que definir un arquetipo de toda la arquitectura renacentista, sin duda serian precisamente las superficies esféricas. Resulta, por tanto, obvio insistir en la importancia de las trazas estereotómicas de este modelo, ya que encierra la clave de toda la estereotomía del dieciséis. La traza de los patrones de este tipo de bóvedas reserva algunas sorpresas interesantes como posteriormente tendremos ocasión de ver con mayor profundidad.

El único dato que necesita el cantero para tallar las dovelas de una cúpula es el patrón de la cara interior de dicha dovela, más concretamente necesitará un patrón distinto por cada hilada de dovelas horizontales en que haya despiezado la bóveda.

Para conocer exactamente estos patrones, el tracista proyectará la silueta de la dovela sobre un plano que pase por sus cuatro vértices; este plano corta al eje vertical en un punto que servirá para abatir el plano y conocer la proyección de la dovela sobre el mismo con toda exactitud (véase fig. K). La misma operación habrá de repetirse con las dovelas de todas las hiladas.

Esta operación geométrica, que aparentemente no parece tener mayores consecuencias, implica, como a continuación veremos, importantes consideraciones.

Efectivamente, pensemos que si vamos inscribiendo todas las dovelas de una hilada en sus correspondientes planos tangentes, al terminar de dar la vuelta a la cúpula, se ha construido una pirámide poligonal que infinitesimalmente podrá considerarse como un cono. Por tanto, si lo que queremos es conocer la proyección plana de una dovela, lo que podemos hacer es desarrollar esta superficie cónica sobre la que los cuatro vértices de una dovela cualquiera habrán delimitado la silueta del patrón que buscamos (véase fig. L.a y b). No en vano en apartados anteriores hubo ocasión de conocer algunos aspectos, a través de las trompas, de los desarrollos de las superficies cónicas. 

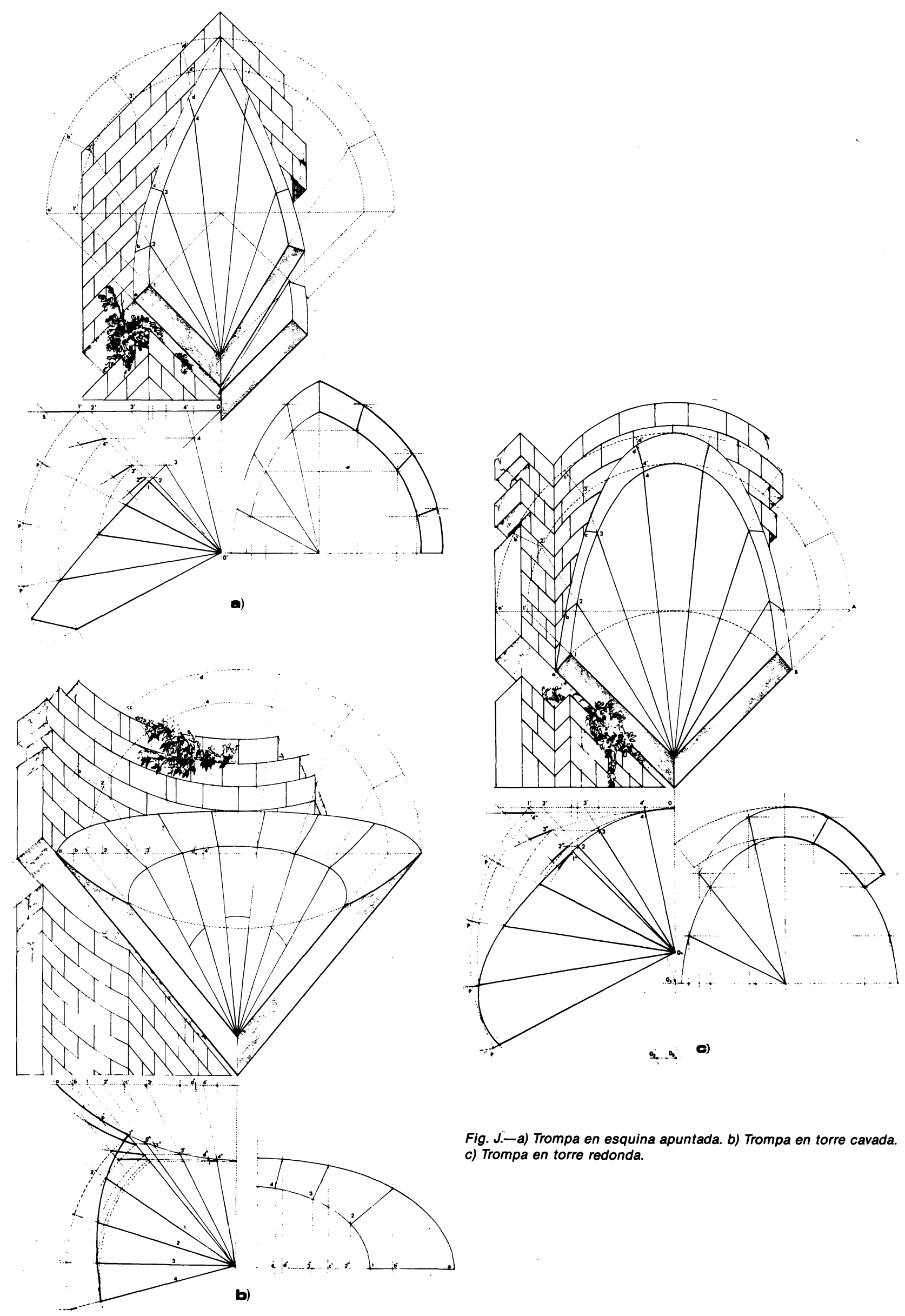

Fig. J.-a) Trompa en esquina apuntada. b) Trompa en torre cavada. c) Trompa en torre redonda. 


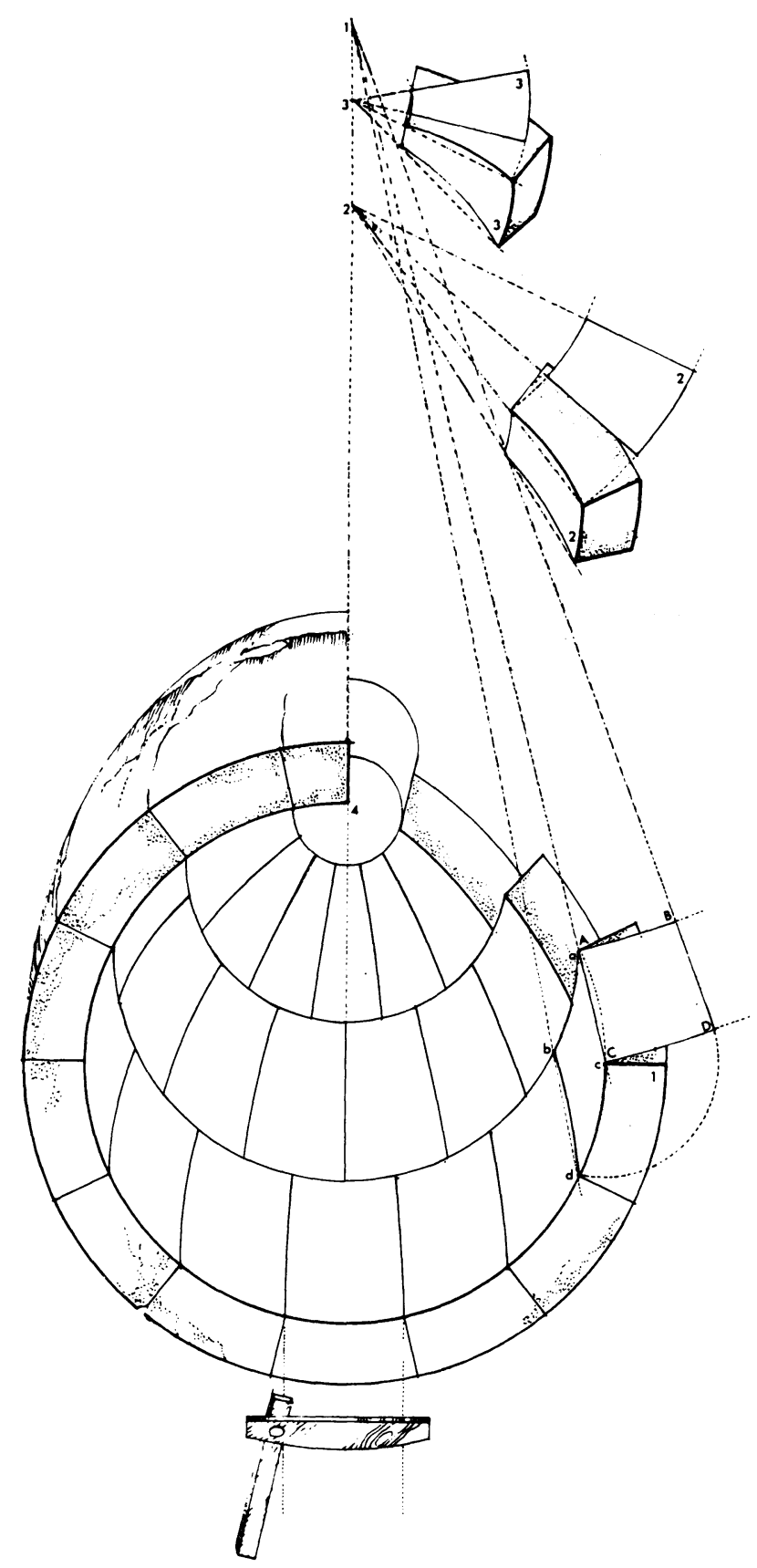

Fig. K.-Diseño de patrones y baibel de la bóveda esférica.

Resulta, por tanto, interesante, a la hora de especular sobre las posibles traslaciones de conocimientos constructivos a lo largo de los distintos periodos históricos, el que sean precisamente las trompas, un instrumento de larga tradición medieval rápidamente abandonado durante el Renacimiento, las que guarden el secreto que permite acometer la mayor parte de las superficies abovedadas.

(C) Consejo Superior de Investigaciones Científicas Licencia Creative Commons 3.0 España (by-nc)
Una vez hallados los patrones, resta ahora proceder a la talla de las dovelas. Esta operación requiere, previamente, la fabricación de un baibel, tal y como indica la figura K. Así pues, se construirá un baibel que tenga uno de sus brazos curvados con la misma curvatura que el diámetro de la bóveda y el otro brazo, recto, orientado hacia el centro de ésta. Los dibujos de la figura $L$ ilustran sobre la forma en que ha de procederse para que, una vez "calcada" la silueta del patrón sobre el prisma de piedra capaz, con la diestra aplicación del baibel, ir obteniendo el volumen de la dovela.

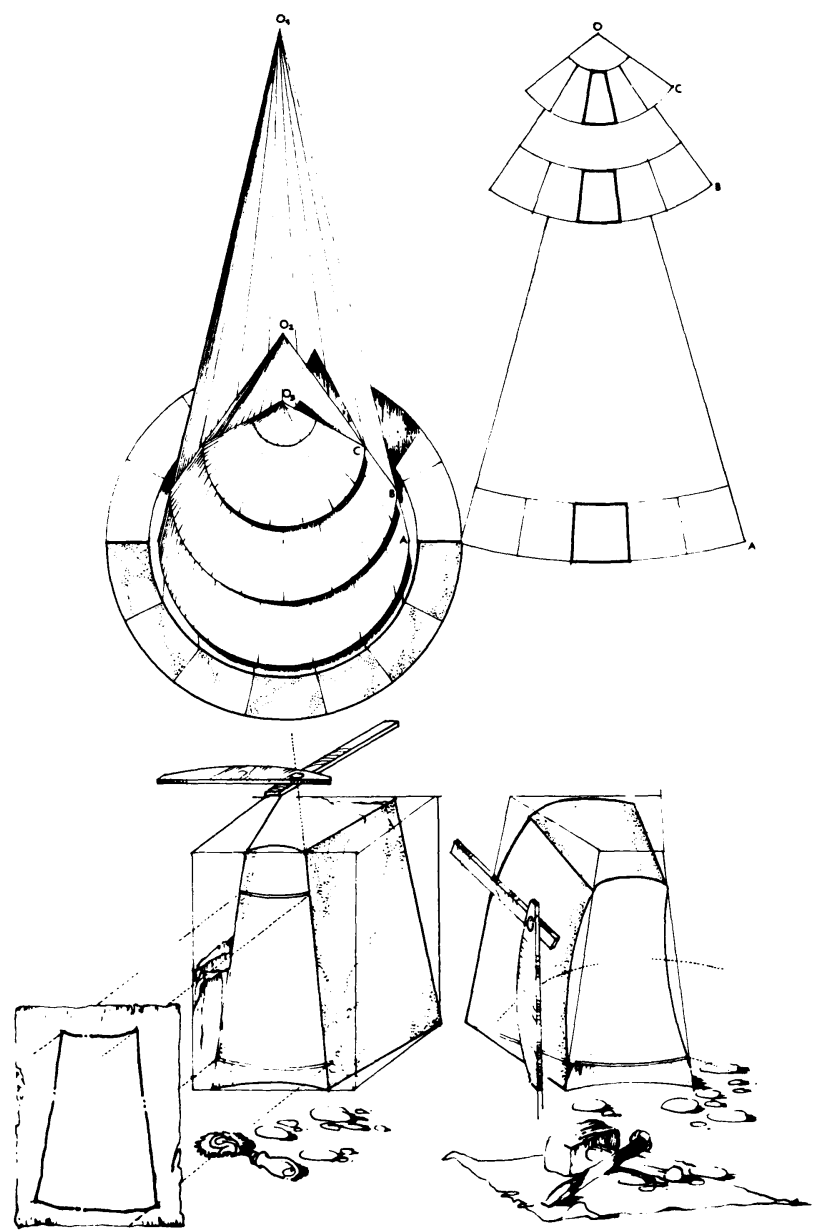

Fig. L.-Desarrollo de superficies cónicas en la cúpula de media naranja y talla de sus dovelas mediante baibel.

http://informesdelaconstruccion.revistas.csic.es 


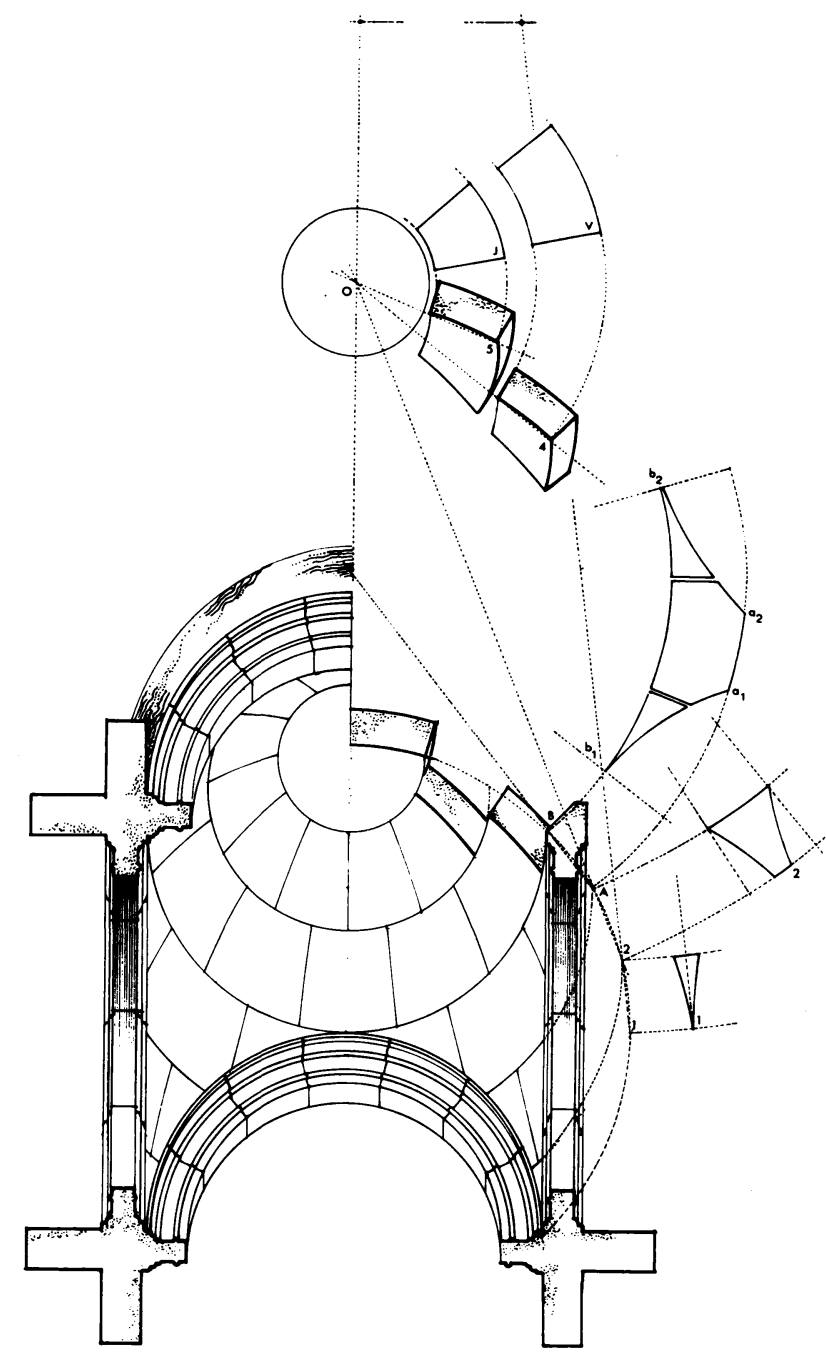

Fig. M.-Bóveda vaída de dovelaje en "vuelta redonda".

\section{Las bóvedas vaídas}

La tercera "gran bóveda" del Renacimiento, después de la cúpula esférica y la bóveda por aristas, es, sin duda, la bóveda vaída. El primer ejemplo que vamos a tratar es la llamada bóveda vaída en "vuelta redonda". Prestemos atención a esta expresión porque es fundamental. Se refiere al hecho de que las dovelas giran circularmente en hiladas alrededor del eje vertical (véase fig. M). Tendremos ocasión, más adelante, de conocer otras formas de disponer el dovelaje. No obstante, esta es, seguramente, la bóveda vaída más clásica y frecuente. Es, en realidad, una semiesfera cortada por cuatro planos que forman, al seccionar la bóveda, los cuatro arcos torales de sustentación. Es por esto que es fácil imaginar que su proceso de talla va a ser muy similar al de la media naranja.

Pensemos, pues, que se trata, a todos los efectos, de construir una semiesfera repartida en seis hiladas; así, pues, comenzaremos a diseñar sus patrones mediante el oportuno desarrollo de superficies cónicas, tal y como anteriormente se ha tenido ocasión de proceder.
Tomemos, a título de ejemplo, la hilada tres. Esta hilada podría llevar inscrito un cono cuyo vértice es el punto $\mathrm{O}_{3}$ situado sobre el eje vertical. Es evidente que para localizar este punto tendremos que reconstruir la silueta de la sección de la bóveda, interrumpida por el arco toral. El punto $\mathrm{O}_{3}$ se obtiene sin más que trazar una recta que pase por los dos puntos que delimitan esta tercera hilada A y $B$.

Para desarrollar este cono, bastará con hacer centro en $\mathrm{O}_{3} \mathrm{y}$, mediante el compás, se trazarán dos círculos, uno con radio $0_{3} \mathrm{~B}$ y otro de radio $0_{3} \mathrm{~A}$. Con ello se tienen ya delimitadas la anchura y curvatura de los patrones de esta tercera hilada. Si esta hilada fuera completa, como es el caso de la cuatro y cinco, el problema estaría ya resuelto, bastaría con trocear como se quisiera esta banda, pero resulta que esta tercera hilada es la primera que debe comenzar a hacer inglete entre los dos arcos torales; por tanto, requiere un despiece al que hay que prestar cierta atención.

Si se observa la bóveda, puede apreciarse cómo esta tercera hilada está dividida en tres piezas, dos triangulares y una de seis lados en el centro. Comencemos, pues, con el círculo de radio $0_{3} \mathrm{~B}$ y traslademos las medidas superiores de estas tres piezas. Estas medidas podrán tomarse de una planta o directamente de la perspectiva. Hagamos después lo propio con el círculo de radio $\mathrm{O}_{3} \mathrm{~A}$, con lo cual tenemos ya los cuatro puntos que definen la silueta completa de esta tercera hilada.

Las uniones curvas de sus laterales requieren, para su trazado exacto, el hallar dos puntos intermedios entre A y B. Por último, para trocear la pieza completa que se acaba de diseñar, bastará con trazar radios desde el centro 0,3 , con lo cual se han obtenido ya los patrones de esta tercera hilada; las sucesivas, siguiendo criterios similares a los expuestos, no ofrecen mayores dificultades. Por último, y en lo que respecta a la talla de las dovelas, usaremos un sólo baibel, lo mismo que para todas las cúpulas esféricas.

\section{La capilla cuadrada por hiladas cuadradas}

La bóveda que a continuación vamos a comentar presenta un tema interesante; se trata del hecho, bien distinto, que supone la construcción de una superficie esférica y la forma en que se decida disponer las hiladas de dovelas. El ejemplo que ahora presentamos es de nuevo una bóveda vaída, de forma similar a la anterior pero con la particularidad de disponer las hiladas formando cuadrados (fig. N).

En realidad, se trata ahora de hacer girar las hiladas de dovelas, no ya alrededor del eje vertical, como era el caso de la bóveda anterior, sino que el dovelaje se 


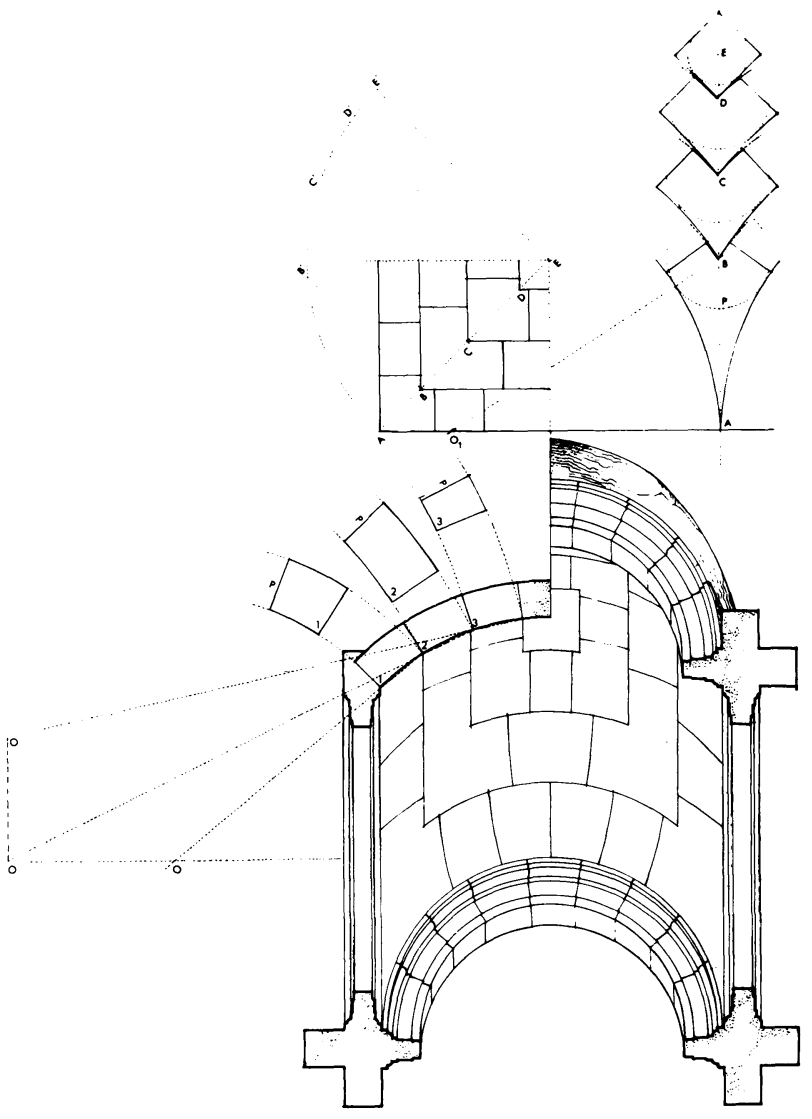

Fig. N.-Bóveda vaida de dovelaje por "hiladas cuadradas".

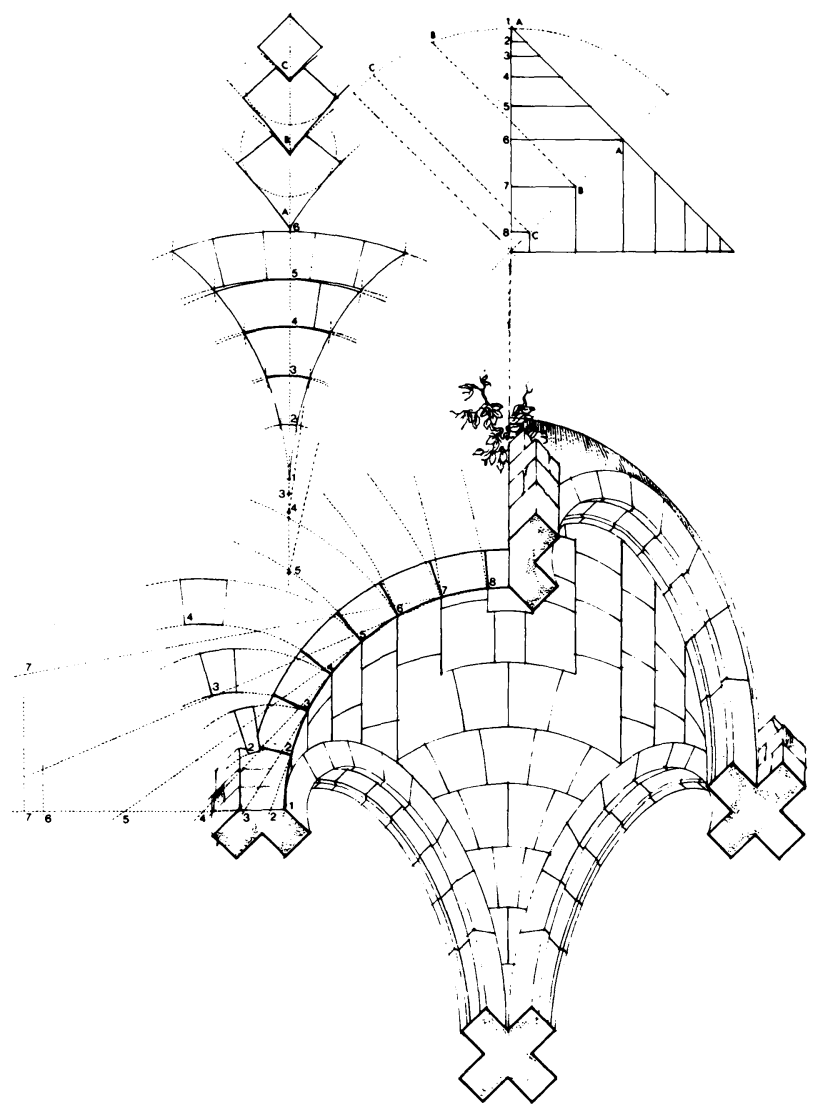

Fig. O.-Bóveda vaída que resuelve su dovelaje por "hiladas diferentes". va a disponer girando circularmente alrededor de los ejes de simetría que unen los centros de los arcos.

Es por esto que el problema de diseño de patrones de las caras de intradós hemos de plantearlo ahora me. diante el desarrollo de superficies cónicas, como siempre, pero con la diferencia de que los vértices de los conos habrán de estar situados en el plano de impostas, en lugar del eje vertical, exactamente sobre los ejes de simetría que pasan por los centros de los arcos. Por lo demás, el proceso de traza de patrones es similar al de la bóveda vaída por hiladas redondas, bastará con buscar los vértices de los conos sobre los ejes horizontales y con el compás trazar las bandas que definen los patrones de cada hilada.

El problema de esta capilla es que las hiladas deben fundirse unas con otras en los rincones y este fundido debe hacerse mediante una colección de piezas esquineras. Bien es verdad que este enlace de hiladas se resuelve frecuentemente en la realidad por "solapes", pero el rigor de una buena ejecución demanda la talla de estas dovelas en inglete.

Su diseño requiere un proceso cuidadoso que se resume en una extensión, por puntos, de esta parte de la bóveda sobre el plano horizontal. Los dibujos 2 y 3 de la figura $\mathrm{N}$ ilustran sobre este particular, aún cuando aquí no nos extendremos en explicaciones más dilatadas.

\section{La autonomía del dovelaje}

La capilla cuadrada por hiladas cuadradas introduce un tema de extraordinaria importancia, cual es el hecho de que el dovelaje de la bóveda pueda disponerse autónomamente sobre la superficie esférica de ésta.

llustraremos este aspecto con otra bóveda vaída que en este caso dispone sus hiladas de dovelas girando alrededor de ejes horizontales, como era el caso anterior. No obstante, ahora estos ejes en lugar de enlazar los centros de los arcos, se van a disponer en posición coincidente con las diagonales.

El aspecto usual de estos dovelajes es, por la limitación que la superficie esférica de la bóveda sufre al ser seccionada por los cuatro arcos, el de unos abanicos de dovelas que naciendo de las impostas van rellenando los ingletes entre los arcos. Una vez salvados éstos, las hiladas ya completas comienzan a describir cuadrados concéntricos girados $45^{\circ}$ respecto a la planta de la bóveda.

Desde un punto de vista constructivo, este tipo de bóvedas, como cabe suponer, se rige por los mismos principios que la que la han precedido, es decir, desarro- 


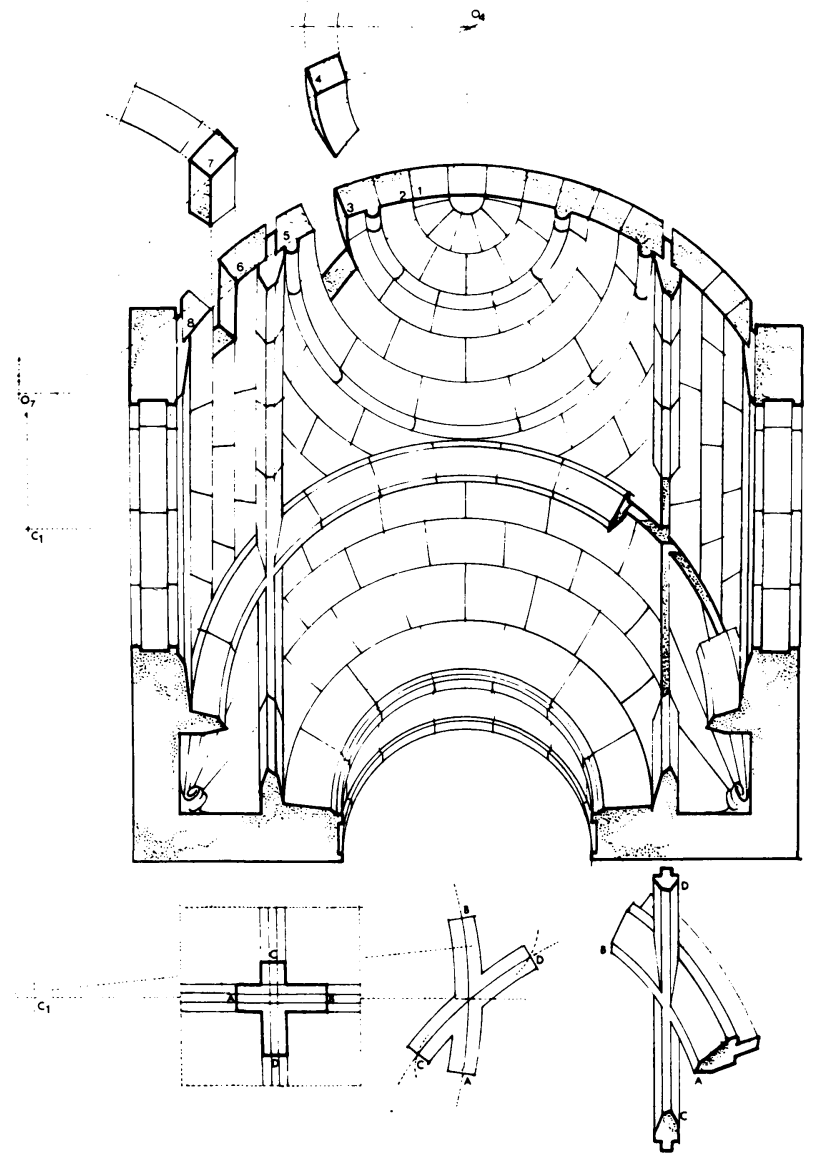

Fig. P.-Bóveda vaída del convento de San Francisco. Baeza.

llos cónicos de los centros dispuestos sobre las diagonales.

Esta autonomía entre la forma de la bóveda y la disposición del dovelaje permite, lógicamente, la introducción de nuevas formas expresivas sobre la superficie de la bóveda, ya que, indudablemente, serían posibles combinaciones entre los despieces de dovelas que acabamos de exponer.

La figura P muestra la estereotomía de la bóveda que Andrés de Vandelvira construyera en la capilla del Convento de San Francisco de Baeza, hoy desaparecida (13). En esta bóveda se combinan comenzando por la clave, una disposición de dovelas que giran por anillos alrededor del eje vertical. Sus patrones, por tanto, habrán de sacarse a través de los correspondientes centros sobre este eje. Posteriormente, las dovelas comienzan a describir cuadrados haciendo girar las hiladas de éstas alrededor de los ejes horizontales de simetría. Los centros que permitirán diseñar los patrones de estas hiladas, habrán de buscarse sobre estos ejes.

Lleva también esta bóveda un juego de cuatro cruceros de "molde revirado" y, por último, cubre sus rincones con cuatro trompas ortogonales en esquina que podrán ir decoradas con veneras al gusto del maestro, como el propio Vandelvira insinúa en su manuscrito. Esta bóveda de Baeza resulta particularmente interesante como resumen de algunas de las consideraciones que a lo largo de este artículo se han ido exponiendo. Vandelvira no sólamente resuelve, con extraordinaria sabiduría, la sintaxis entre el doble juego que establece la forma espacial y el diseño del dovelaje, sino que, además, encuentra ocasión de introducir cuatro trompas, cuyas concavidades cónicas constituyen un homenaje formal a los principios que rigen toda la estereotomía del Renacimiento.

\section{NOTAS}

1. Véase Gómez Moreno, Manuel. "Las Aguilas del Renacimiento español”, Madrid, C.S.I.C., Instituto Diego Velázquez, 1941.

2. Pérouse de Montclos. "L'architecture a la française", Edit. Picard, 1982.

3. Chueca Goitia, Fernando. "La Catedral Nueva de Salamanca”, págs. 124-129.

4. Bails, Benito. "Diccionario de Arquitectura Civil", Madrid, 1802.

5. Vandelvira, A. de. "Libro de traças de cortes de piedra...", Biblioteca de la Escuela Técnica Superior de Arquitectura de Madrid, Mss. Sig. 10. Existe de este manuscrito una edición facsímil: "Tratado de arquitectura de Andres de Vandelvira", por Genevieve Barbe-Coquelin, Albacete (Caja de Ahorros Provincial), 1977, 2 vol.

6. Navascués Palacio, Pedro, "El manuscrito de Arquitectura de Hernán Ruiz el Joven”, Escuela Técnica Superior de Arquitectura de Madrid, 1974.

7. Ginés Martínez de Aranda. "Cerramientos y trazas de montea", Edición facsímil, Biblioteca CEHOPU.

8. Camón Aznar, José. "La intervención de Rodrigo Gil de Hontañón en el manuscrito de Simón García", Archivo Español de Arte, 1941, también: "Compendio de Arquitectura y simetría de los templos", Universidad de Salamanca, 1941.

9. Philibert de L'Orme. "Architecture", París, 1561, edición facsímil Pierre Mardagá, editor, versión íntegra 1648, Bruselas, 1981.

10. Guarini, Guarino, "Architectura civile" 17371, reedición Milán, 1968.

11. Véase Bails, op. cit. Definición del arte de la montea, "EI dibujo que se hace de una bóveda de tamaño natural en una pared o suelo para tomar medidas y formas de sus diferentes partes".

12. Véase al respecto algunas explicaciones en el tratado de P. Derand, "L'architecture des voutes...", París, S. Cramoisy 1643.

13. Chueca Goitia, Fernando. "Andrés de Vandelvira Arquitecto", Jaén, 1971, donde podrán encontrarse interesantes reflexiones sobre esta bóveda. 